\title{
Optimization Research on the Multilayer Wall Integrated with a PCM Layer
}

\author{
Feng Tao ${ }^{1,2, *}$, Ya Wang ${ }^{2}$ and Xi Meng ${ }^{3}$ \\ ${ }^{1}$ University of Science and Technology of China; ${ }^{2}$ Department of Architectural Engineering, HeFei University, Hefei 230601, \\ PR China; ${ }^{3}$ College of Architecture and Environment, Sichuan University, China
}

\begin{abstract}
The phase change material (PCM) used in a building wall can reduce building energy consumption and improve the living comfort level. However, only when the temperature of the PCM layer is between phase transition temperature ranges can it have the maximum effect to increase the thermal inertia. How to select the suitable PCM according to the local weather and building wall always troubles building engineers and affects the wide use of PCM on building energy efficiency. Aiming at present situation, this paper numerically analyzed the energy conservation of building multilayer wall integrated with a PCM layer to optimize PCM thermophysical properties and wall structure under the Chengdu typical climates of winter, summer and transition seasons. The numerical simulation used the heat transfer model of the enthalpy-porosity technique, which was verified by the experiment. The results show that the PCM layer can decrease the building annual load, increase the time lag, decrease the decrement factor and improve occupants' comfort. When the phase change occurs under the suitable temperature conditions, high latent heat is conducive to decreasing the heat flow fluctuation, increasing the time lag and improving inner surface temperature stability. It is more efficient that the PCM layer is located next to the internal surface and under this condition, the optimum solidus and liquidus temperatures are $14^{\circ} \mathrm{C}$ and $26^{\circ} \mathrm{C}$ respectively, under the Chengdu climates. And the annual inner surface heat flow can be reduced up to $13.36 \%$ for the PCM layer of $30 \mathrm{~mm}$ and $9.64 \%$ for the PCM layer of $20 \mathrm{~mm}$ compared with no the PCM layer.
\end{abstract}

Keywords: Energy conversation, heat flow, PCM, thermophysical properties.

\section{INTRODUCTION}

With the continuous improvement of living standard and indoor comfort, the building energy consumption is growing very quickly and the building energy efficiency has been very urgent [1]. Energy storage can reduce the time and rate mismatch between energy supply and demand, thereby playing a vital role in energy conservation [2]. Compared with the sensible heat storage system, the phase change material (PCM) becomes popular due to its higher energy storage density and smaller masses and volumes of material. So PCM has been widely used in many engineering fields, such as heating and cooling [3], solar energy storage [4], food preservation [5], cooling of electronic components [6] and so on. In recent years, the PCM building envelope has been researched by many researchers [7]. Compared with traditional building envelope, the thermal mass of building envelope integrated with the PCM layer was increased greatly, which would reduce the building energy consumption, improve the indoor thermal comfort, and shift the peak electricity load [8].

Yan et al. [9] experimentally researched the thermal properties of the PCM wall formed by three different methods. Their results show that the addition of PCM in traditional walls can decrease building consumption and reduce the indoor air temperature fluctuation. And energy-saving

\footnotetext{
*Address correspondence to this author at the University of Science and Technology of China; Tel: 15056070404 ; E-mail: tf123@vip.sina.com
}

effect of phase change walls prepared by lamination interpolation method is better than walls prepared by direct mixing method. Mandilaras et al. [10] built a two-story typical family house outfitted with PCM walls. The results showed that the wall thermal mass was enhanced during late spring, early summer and autumn. The decrement factor was reduced by $30-40 \%$ and the time lag was increased by approximately 100 min. Sa et al. [11] developed a new composite material embedded with the microencapsulated PCM in plastering mortar. It was found that the peak temperature of indoor air was reduced by $2.6^{\circ} \mathrm{C}$ when the PCM mortar was used. In addition, Jin et al. $[2,12]$ experimentally studied the placement of a PCM thermal shield within the cavity of buildings walls. Their results show that, compared to a wall without a PCM layer, the peak heat flows were reduced by as much as $11 \%$ when the thermal shield was placed in the inward-most location next to the internal surface of the gypsum wallboard within the wall cavity. The PCM thermal shield produced only small effects on the peak heat flows when it was placed half way between the enclosing surfaces of the internal cavity of the wall and almost no effect when it was placed next to the internal surface of the outermost layer. Wang et al. [13] studied the ultrathin envelope thermal performance improvement of the prefab house by integrating with PCM numerically under the Chengdu climates. Results show that the small PCM heat conductivity coefficient, large phase change latent heat of PCM, low phase transition temperature range and the PCM layer locating at inner side can obtain the excellent thermal performance of ultrathin envelope integrated with PCM. 
However, compared with the traditional building wall, there has been a lack of comprehensive research on the optimum choice of PCM thermophysical properties and wall structure integrated with the PCM layer under the specific climate conditions. In this paper, the heat transfer about the multilayer wall integrated with PCM has been established and verified by the published papers. And then, the influence of latent heat, phase change temperature, placement and thickness of the PCM layer was researched on the inner heat flow and the temperature decrement factor.

\section{PHYSICAL DESCRIPTION AND HEAT TRANSFER MODEL}

\subsection{Physical Description}

The building walls are three-dimensional, but their heat transfer is considered to be one-dimensional between inner and outer surfaces. For the simplified calculation, the multilayer wall integrated with a PCM layer can be assumed as the two-dimensional (2-D) model as shown in Fig. (1). As shown in Fig. (1), the height and thickness of wall model are $600 \mathrm{~mm}$ and $240 \mathrm{~mm}+b$ respectively, where $240 \mathrm{~mm}$ is the sum of the brick layer thicknesses at the PCM layer sides and $b$ is the PCM layer thickness. And the distance between the PCM layer and outer surface is $L$. Table 1 shows the thermophysical properties of each layer materials.

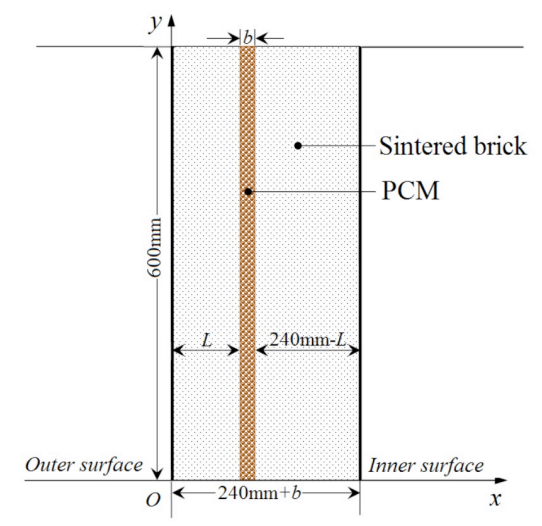

Fig. (1). The section schematic diagram of the multilayer wall integrated with a PCM layer.

\subsection{Heat Transfer Model}

According to the wall model in Fig. (1), the 2-D system of coordinate is established with the wall thickness direction of $x$ and the wall height direction of $y$. Under outside varying air temperature conditions, wall heat transfer is an unsteady heat conduction process containing PCM melting and solidification in the multilayer wall integrated with the PCM layer. Therefore, in the present study, an enthalpy-porosity technique is utilized to simulate such dynamic heat transfer process [14], and the governing equation is:

$\frac{\partial(\rho H)}{\partial t}=\frac{\partial}{\partial x}\left(\lambda \frac{\partial T}{\partial x}\right)+\frac{\partial}{\partial y}\left(\lambda \frac{\partial T}{\partial y}\right)$

Where, $\rho$ is the material density, $\mathrm{kg} / \mathrm{m}^{3} ; H$ is the material enthalpy value; $\lambda$ is the thermal conductivity, $\mathrm{W} /(\mathrm{m} \cdot \mathrm{K}) ; T$ denotes the material temperature, ${ }^{\circ} \mathrm{C} ; t$ is time, $\mathrm{s}$;
Table 1. Thermophysical properties of materials.

\begin{tabular}{|c|c|c|c|}
\hline Material & Density & $\begin{array}{c}\text { Special heat } \\
\text { capacity }\end{array}$ & Thermal conductivity \\
\hline \hline Brick & 1700 & 1051.6 & 0.63 \\
\hline PCM & 1300 & 1785 & $\begin{array}{c}0.25 \text { (phase), } \\
0.50 \text { (solid or liquid) }\end{array}$ \\
\hline
\end{tabular}

In the brick layer, the material enthalpy value, $H$, can be shown as:

$H=c_{b} T$

Where, $c_{b}$ expresses specific heat, $\mathrm{J} /(\mathrm{kg} \cdot \mathrm{K})$;

In the PCM layer, melting and solidification will occur intermittently under outside varying air temperature conditions. In the enthalpy-porosity model, the phase change does not actually occur and the liquid fraction is introduced and defined as follows:

$\beta= \begin{cases}0 & \left(T<T_{S}\right) \\ \left(T-T_{S}\right) /\left(T_{L}-T_{S}\right) & \left(T_{S} \leq T \leq T_{L}\right) \\ 1 & \left(T>T_{L}\right)\end{cases}$

Where, $T_{S}$ and $T_{L}$ are solidus and liquidus temperatures of the PCM, respectively.

Therefore, in the PCM layer, the material enthalpy value can be defined as:

$H=\int_{0}^{T} c_{p} d t+\beta L_{P}$

Where, $c_{p}$ expresses the PCM specific heat, $\mathrm{J} /(\mathrm{kg} \cdot \mathrm{K}) ; L_{P}$ is the PCM latent heat, $\mathrm{J} / \mathrm{kg}$;

Convective heat transfer boundary conditions are adopted on outer and inner surfaces, and adiabatic boundary conditions can be used on the top and bottom surfaces and they can be expressed as:

On the outer surface:

$-\left.\lambda \frac{\partial T}{\partial x}\right|_{x=0}=h_{\text {out }}\left(T_{\text {out }}-T_{l, o u t}\right)+\alpha I-T_{r}$

On the inner surface:

$-\left.\lambda \frac{\partial T}{\partial x}\right|_{x=240 m m+b}=h_{\text {in }}\left(T_{1, \text { in }}-T_{\text {in }}\right)$

On the top and bottom surfaces:

$-\left.\lambda \frac{\partial T}{\partial y}\right|_{y=0,600 \mathrm{~mm}}=0$

Where, $h_{\text {in }}$ and $h_{\text {out }}$ are inside and outside convective heat transfer coefficients, $\mathrm{W} /\left(\mathrm{m}^{2} \cdot \mathrm{K}\right) ; T_{\text {out }}$ and $T_{\text {in }}$ are indoor and outdoor air temperatures, ${ }^{\circ} \mathrm{C} ; T_{1, \text { out }}$ and $T_{1, \text { in }}$ are outer and inner surface temperatures ${ }^{\circ} \mathrm{C} ; \alpha$ is absorption coefficient, $\mathrm{W} / \mathrm{m}^{2} . T r$ is wall effective long wave temperature, ${ }^{\circ} \mathrm{C}$.

To research the thermal inertia of the multilayer wall integrated with the PCM layer, the temperature decrement factor has been introduced and defined as follows: 


$$
A=\frac{\left(T_{l, \text { in }}\right)_{\max }-\left(T_{l, \text { in }}\right)_{\min }}{\left(T_{l, \text { out }}\right)_{\max }-\left(T_{l, \text { out }}\right)_{\min }}
$$

\subsection{Wall Heat Transfer Model}

The finite volume method is utilized to discretize the heat transfer model equation in the simulation region. For the discretization, the central differencing algorithm is used for the two-order implicit scheme, and the SIMPLE algorithm is utilized to solve the governing Eq. (1) with the corresponding boundary conditions given in Eqs. (2)-(4).

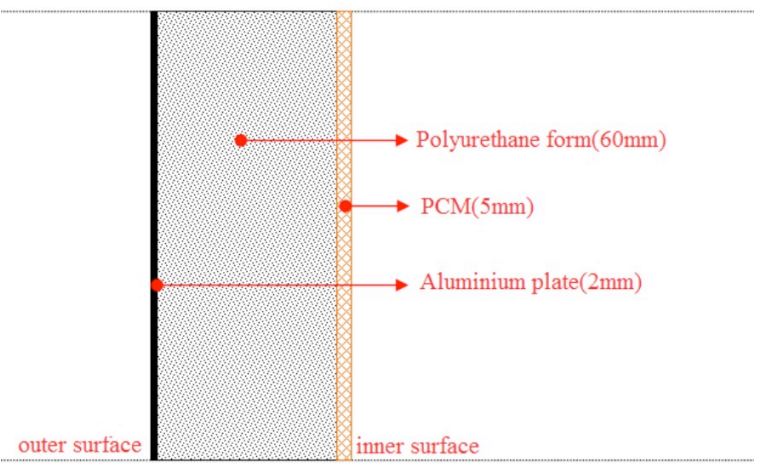

Fig. (2). The PCM wall model $[14,15]$.

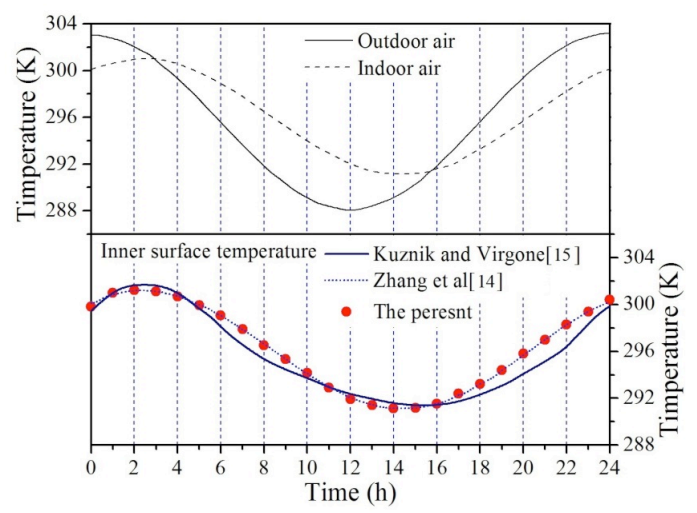

Fig. (3). Indoor and outdoor air temperatures and comparison of inner surface temperature with experiment [15] and simulation [14].

\section{WALL HEAT TRANSFER MODEL}

To verify the accuracy and reliability of the unsteady calculation procedure on the enthalpy-porosity model, the dynamic thermal response of the multilayer wall integrated with the PCM layer is researched experimentally by Kuznik and Virgone [15] and numerically by Zhang et al. [14]. Fig. (2) shows the section schematic diagram of the PCM wall model researched by Kuznik and Virgone [15] and Zhang et al. [14]. Fig. (3) shows outside and inside air temperature fluctuations and compares the present results with experimental and numerical results $[14,15]$. The present results agree well with the experimental results of Kuznik and Virgone [15] and numerical results of Zhang et al. [14]. Especially for numerical results of Zhang et al. [14], their results are almost equate, which shows that this calculation procedure has the high accuracy.

\section{INFLUENCE OF THE PCM THERMOPHYSICAL PROPERTIES}

The present research still uses the 2-D model in Fig. (1), where the wall physical dimension is shown. The PCM thermophysical properties have been mainly researched in this section, so $b=20 \mathrm{~mm}$ and $L=240 \mathrm{~mm}$. And Table 1 shows the thermophysical properties of each layer material and the PCM latent heat is $178.5 \mathrm{~kJ} / \mathrm{kg}$ and solidus and liquidus temperatures of the $\mathrm{PCM}$ are $18^{\circ} \mathrm{C}$ and $26^{\circ} \mathrm{C}$ respectively, and $\operatorname{Tr}=1.8^{\circ} \mathrm{C}$.

Fig. (4) shows outside air temperature and solar radiation intensity during $24 \mathrm{~h}$ of January, July and October under Chengdu typical climates. January, July and October stand for winter, summer and the transition season, respectively. The inside convective heat transfer coefficient is $8.7 \mathrm{~W} /\left(\mathrm{m}^{2} \cdot \mathrm{K}\right)$, while the outside heat transfer coefficient is $21 \mathrm{~W} /\left(\mathrm{m}^{2} \cdot \mathrm{K}\right)$ in winter and $19 \mathrm{~W} /\left(\mathrm{m}^{2} \cdot \mathrm{K}\right)$ in other seasons. The wall absorption coefficient is 0.6 and the wall boundaries are referred to Eqs. (5)-(7). In addition, the grid independent and time step solution was tested and the final quantities of grid and test step are 99400 and 60s.

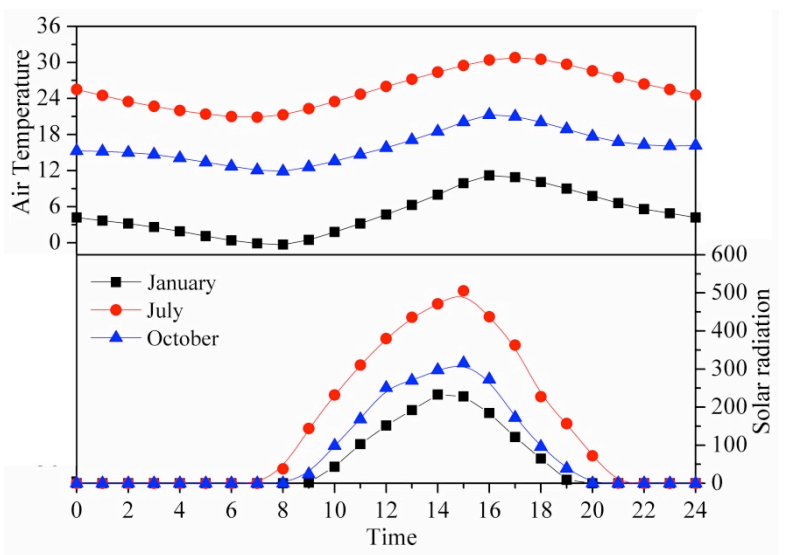

Fig. (4). Outdoor air temperatures and solar radiation under the typical Chengdu climates.

\subsection{The Influence of the PCM Latent Heat}

To obtain the influence of PCM latent heat on wall heat transfer, five latent heat values are selected from $35.7 \mathrm{~kJ} / \mathrm{kg}$ to $321.3 \mathrm{~kJ} / \mathrm{kg}$. Fig. (5) shows heat flow with time under the different PCM latent heat during the typical climates of January, July and October. As shown in Fig. (5), during the January, the inner heat flow remains unchanged with the latent heat increase, which shows the latent heat has not any effect on the inner heat flow in January. This phenomenon can result from that the PCM temperature which is always lower than its solidus temperature; and therefore, PCM has not undergone any phase change. On the other hand, during July and October, the inner heat flow amplitude decreases obviously with the increase of PCM latent heat, which indicates that the PCM layer can improve wall thermal mass significantly. But when the latent heat is more than $178.5 \mathrm{~kJ} / \mathrm{kg}$, the influence of decreasing heat flow amplitude becomes poor. And with the latent heat increase, the peak heat flow is postponed, and correspondingly, the peak electricity load will be shifted and the energy consumption will be reduced. Fig. (6) 
shows the temperature decrement factor with the PCM latent heat under the typical climates. Owing to not any phase change during January, the decrement factor keeps constant with the increase of PCM latent heat. Moreover, during July and October, the decrement factor increases obviously with the increase of PCM latent heat, which indicates the PCM layer can decrease the temperature volatility and improve the indoor comfort level.

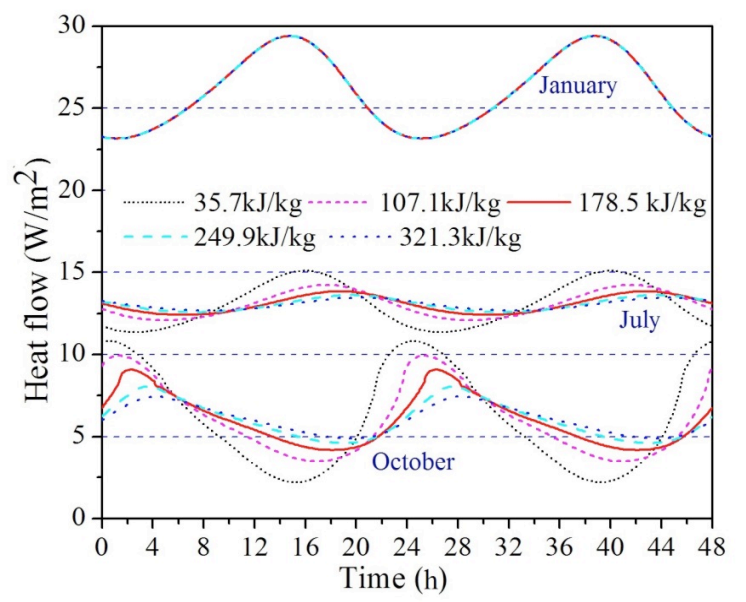

Fig. (5). Inner surface heat flow with time under different PCM latent heat.

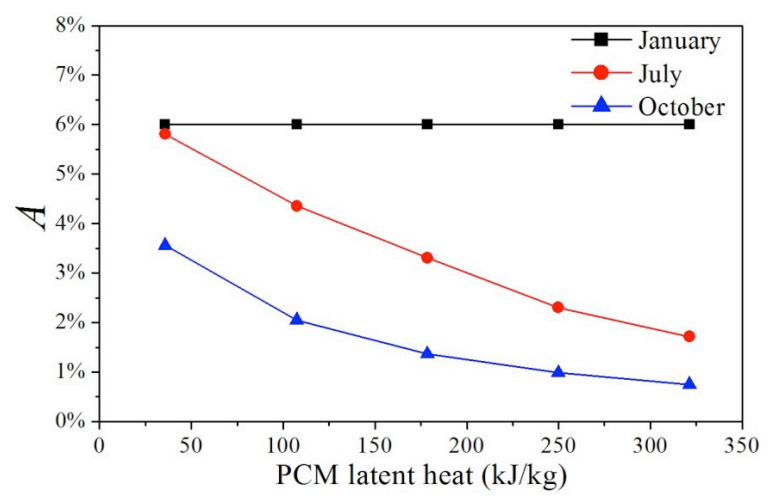

Fig. (6). The temperature decrement factor with the PCM latent heat under the typical climates.

\subsection{The Influence of the PCM Solidus and Liquidus Temperature}

To obtain the influence of PCM solidus and liquidus temperatures on wall heat transfer, two kinds of change forms are considered: translation change with the same temperature difference and scaling change with the same average temperature. Firstly, six groups of solidus and liquidus temperatures $\left(9^{\circ} \mathrm{C} \mathrm{\&} 17^{\circ} \mathrm{C}, 12^{\circ} \mathrm{C} \& 20^{\circ} \mathrm{C}, 15^{\circ} \mathrm{C} \& 23^{\circ} \mathrm{C}\right.$, $18^{\circ} \mathrm{C} \& 26^{\circ} \mathrm{C}$ and $21^{\circ} \mathrm{C} \& 29^{\circ} \mathrm{C}$ and $24^{\circ} \mathrm{C} \& 32^{\circ} \mathrm{C}$ ) are researched. Fig. (7) shows inner surface heat flow with time under the different average value of solidus and liquidus temperatures. In Fig. (7), only three curves can be seen clearly due to that some curves are covered. When the PCM temperature is lower than solidus temperature or higher than liquidus temperature, there is not any phase change under $18^{\circ} \mathrm{C} \& 26^{\circ} \mathrm{C}, 21^{\circ} \mathrm{C} \& 29^{\circ} \mathrm{C}$ and $24^{\circ} \mathrm{C} \& 32^{\circ} \mathrm{C}$ during January, $9^{\circ} \mathrm{C} \& 17^{\circ} \mathrm{C}, 12^{\circ} \mathrm{C} \& 20^{\circ} \mathrm{C}, 15^{\circ} \mathrm{C} \& 23^{\circ} \mathrm{C}$ during July and $9^{\circ} \mathrm{C} \& 17^{\circ} \mathrm{C}, 12^{\circ} \mathrm{C} \& 20^{\circ} \mathrm{C}$ and $24^{\circ} \mathrm{C} \& 32^{\circ} \mathrm{C}$ during October, so that some curves are completely covered. Therefore, the phase change temperature should be lower than $18^{\circ} \mathrm{C}$ in January, more than $23^{\circ} \mathrm{C}$ in July and between $20^{\circ} \mathrm{C}$ and $24^{\circ} \mathrm{C}$ in October for Chengdu climates. Fig. (8) shows the temperature decrement factor with the average phase change temperature. It is clearly seen that optimum average phase change temperature should be lower than $22^{\circ} \mathrm{C}$ in January, more than $19^{\circ} \mathrm{C}$ in July and $16^{\circ} \mathrm{C}-28^{\circ} \mathrm{C}$ in October.

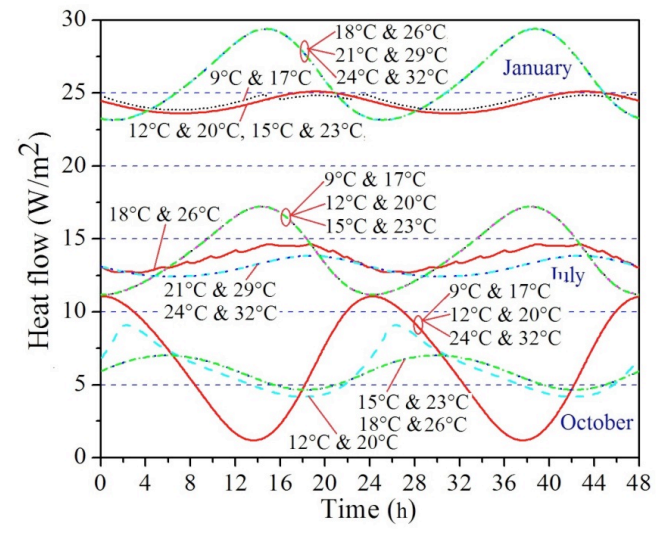

Fig. (7). Inner surface heat flow with time under the different average value of phase change temperature.

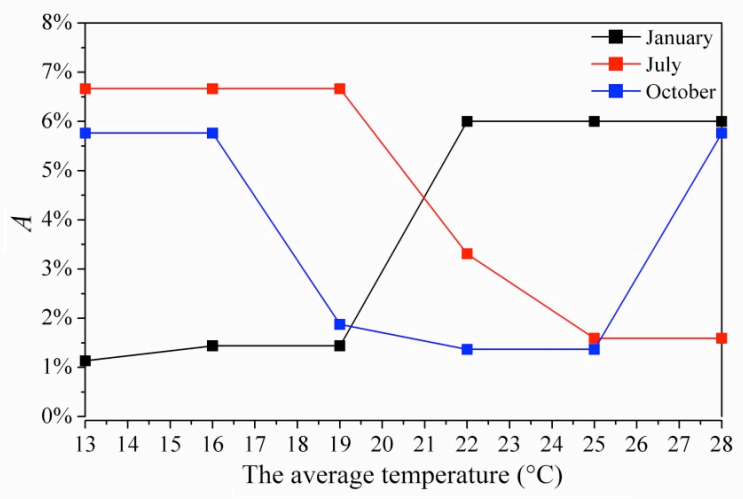

Fig. (8). The temperature decrement factor with the average phase change temperature.

For the phase change temperature and scaling change with the same average temperature, five groups of solidus and liquidus temperature $\left(12^{\circ} \mathrm{C} \& 32^{\circ} \mathrm{C}, 14^{\circ} \mathrm{C} \& 30^{\circ} \mathrm{C}, 16^{\circ} \mathrm{C}\right.$ $\& 28^{\circ} \mathrm{C}, 18^{\circ} \mathrm{C} \& 26^{\circ} \mathrm{C}$ and $20^{\circ} \mathrm{C} \mathrm{\&} 24^{\circ} \mathrm{C}$ ) are researched. Fig. (9) shows the inner surface heat flow with time under the different difference of phase change temperature with $T_{\text {avg }}=22^{\circ} \mathrm{C}$. For January and July, the wide phase change interval is conducive to decreasing heat flow fluctuation due to that wide interval can cover PCM lower temperature in January and higher temperature in July as soon as possible. In addition, because PCM layer temperature fluctuates around $22^{\circ} \mathrm{C}$ in October, which is close to the average phase change temperature, the thin phase change interval can be more efficient.

Fig. (10) shows the temperature decrement factor with the phase change temperature intervals. It is clearly seen that the wide phase change interval can decrease the temperature 
decrement factor in January and July; can increase the temperature decrement factor in October; and can increase the temperature decrement slightly in October.

By combining Figs. ( 7 and $\mathbf{8}$ ), it is easily found that the optimum solidus and liquidus temperature is $14^{\circ} \mathrm{C}$ and $26^{\circ} \mathrm{C}$ respectively, when the PCM layer is located in the inner surface under Chengdu climates.

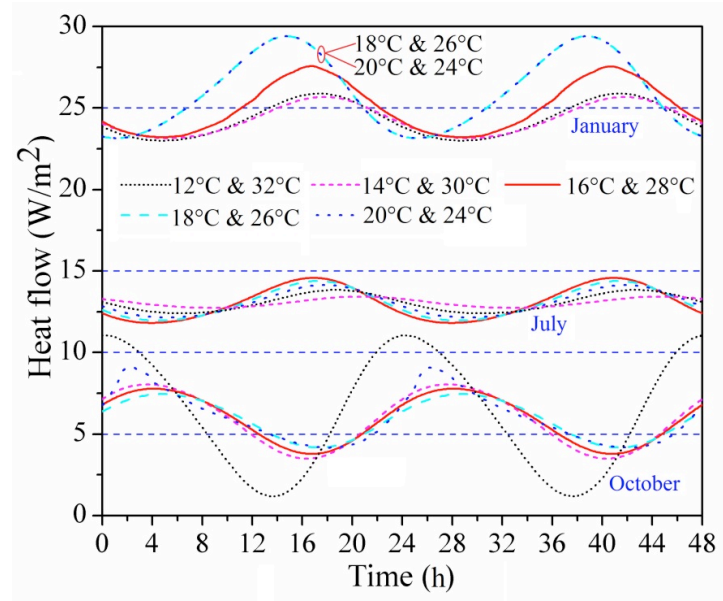

Fig. (9). Inner surface heat flow with time under the different phase change temperature intervals.

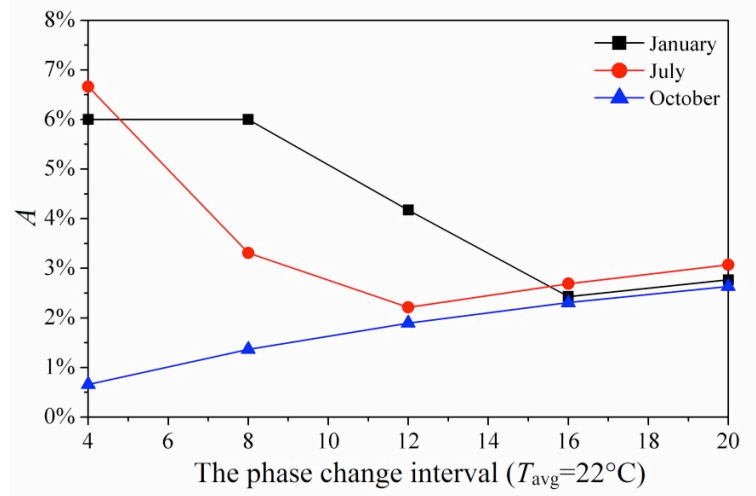

Fig. (10). The temperature decrement factor with the phase change temperature intervals.

\section{INFLUENCE OF THE PCM WALL STRUCTURE}

The PCM wall structure is an important factor affecting wall heat transfer. So in this section, the influence of wall structure is analyzed based on the heat transfer rule with respect to PCM placement and thickness. The PCM thermophysical properties are constant as shown in Table 1, whereas the PCM latent heat is $178.5 \mathrm{~kJ} / \mathrm{kg}$, and solidus and liquidus temperatures are $18^{\circ} \mathrm{C}$ and $26^{\circ} \mathrm{C}$ respectively. The outer air temperature and solar radiation intensity are shown in Fig. (4).

\subsection{Influence of the PCM Layer Location}

To obtain the influence of PCM layer location on wall heat transfer, five PCM layer placements are considered. Fig. (11) shows inner surface heat flow with time under the different PCM layer placements. Due to which the PCM phase change does not occur and that the PCM thermophysical properties with solid phase are similar to those of the construction layer in January, i.e. five curves are coincided under different PCM layer placements. Moreover, in July, heat flow has the greatest volatility and the maximum average value at $L=0 \mathrm{~mm}$ and other four curves remain similar to each other. In addition, in October, the heat flow has the lowest volatility at $L=240 \mathrm{~mm}$ and other four curves remain also similar each other. From the above, it is most conducive to decreasing the heat flow volatility and value when the PCM layer is installed in the inner surface.

Fig. (12) shows temperature decrement factor with the different PCM layer location. It is clearly seen from Fig. (12) that it is conducive to decreasing the temperature decrement factor and improving the inner surface temperature stability, when the PCM layer is installed the inner surface.

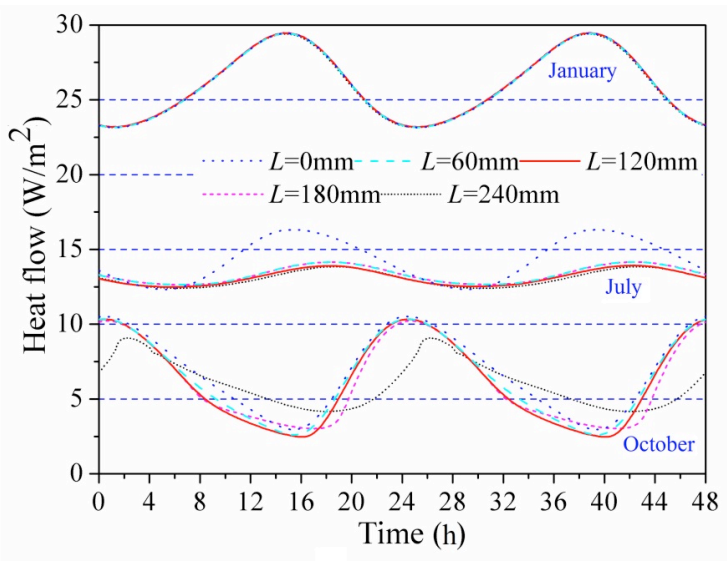

Fig. (11). Inner surface heat flow with time under the different PCM layer locations.

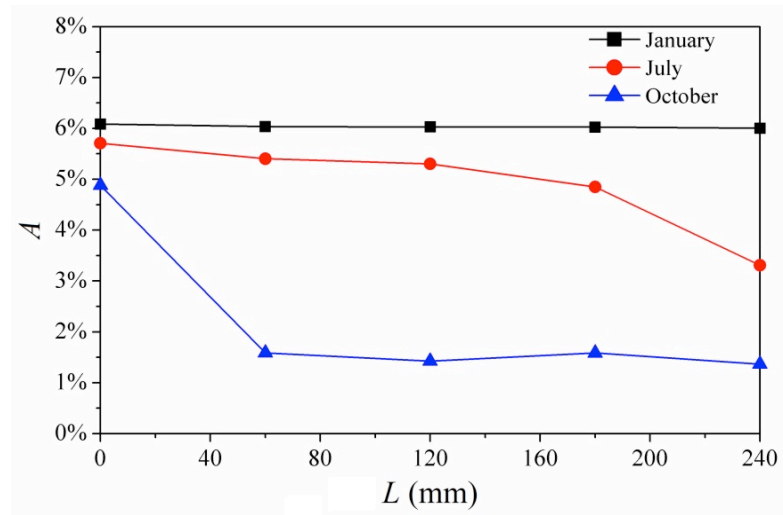

Fig. (12). The temperature decrement factor with the different PCM layer locations.

\section{2, Influence of the PCM Layer Thickness}

To obtain the influence of PCM layer thickness on wall heat transfer, five PCM layer thickness is considered i.e. from 0 to $30 \mathrm{~mm}$. Fig. (13) shows inner surface heat flow with time under the different PCM layer thickness. It is clearly seen that the heat flow amplitude obviously decreases with the increase of the PCM layer thickness in July and October; while the heat flow amplitude has a little reduction due to which the phase change did not occur in the PCM layer in January. It is shown that the PCM layer can increase 
the thermal mass of building walls especially when the phase change occurs.

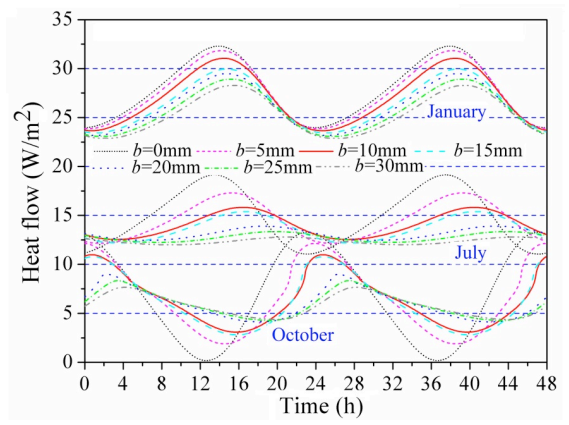

Fig. (13). Inner surface heat flow with time under the different PCM layer thickness.

Fig. (14) shows inner surface average heat flow with the PCM layer thickness and its reduction percentage compared with $b=0 \mathrm{~mm}$. With the increase of the PCM layer thickness, the average heat flow decreases lineally. And the extent of decrement is the highest in October because its outdoor and indoor air temperature fluctuates between solidus and liquidus temperatures; the decrement extent is lower in July and the decrement extent is lowest in January due to not any phase change. Compared with no PCM layer situation, the comprehensive annual decrease percentage is $13.36 \%$ for $b=30 \mathrm{~mm}, 9.64 \%$ for $b=20 \mathrm{~mm}$ and $4.63 \%$ for $b=10 \mathrm{~mm}$ with the consideration of summer climates of three months, winter climates of three months and the transition climates of six months. Fig. (15) shows the temperature decrement factor with the PCM layer thickness. In Fig. (15), the temperature decrement factor decreases with the increase of the PCM layer, which shows the PCM layer can improve indoor temperature stability and occupants' comfort.

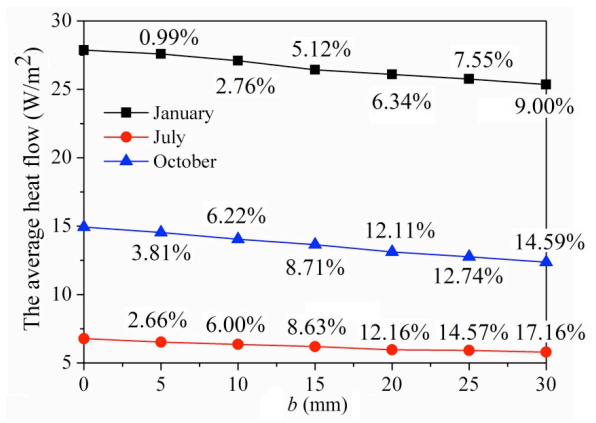

Fig. (14). Inner surface average heat flow with the PCM layer thickness.

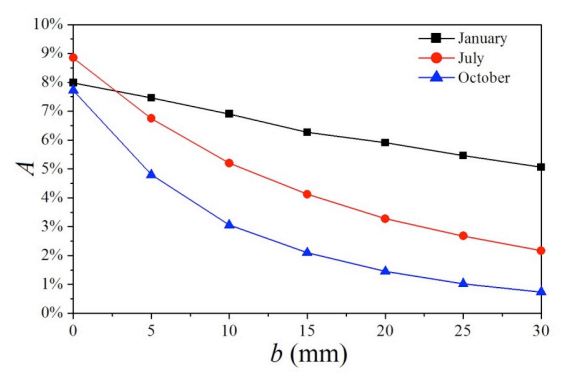

Fig. (15). The temperature decrement factor with the PCM layer thickness.

\section{CONCLUSION}

In this paper, the multilayer wall integrated with the PCM layer is researched under the Chengdu climates and the following conclusion is obtained.

The PCM layer can decrease the building annual load, increase the time lag, decrease the temperature decrement factor and improve occupants' comfort. And the annual inner surface heat flow can be reduced up to $13.36 \%$ for $b=30 \mathrm{~mm}$ and $9.64 \%$ for $b=20 \mathrm{~mm}$ compared with not any PCM layer change.

The optimum placement of the PCM layer is located next to internal surface. And the stronger the heat storage capacity, the smaller the indoor temperature fluctuation is.

The wide phase change temperature interval is conducive to obtaining the best effect throughout the year. And the optimum solidus and liquidus temperatures are $14^{\circ} \mathrm{C}$ and $26^{\circ} \mathrm{C}$ under the Chengdu climates.

\section{CONFLICT OF INTEREST}

The authors confirm that this article content has no conflict of interest.

\section{ACKNOWLEDGEMENTS}

This work was supported by the Natural Science Foundation of Anhui Province Department of Education (No. KJ2012Z341), the Youth Program of Anhui Province Department of Education (No. 2012SQRL173) and Project of Hefei university's key disciplines construction of civil engineering (No. 2014xk04).

\section{REFERENCES}

[1] X. Jin, S. Zhang, X. Xu, and X. Zhang, "Effects of PCM state on its phase change performance and the thermal performance of building walls", Building and Environment, vol. 91: pp. 334-339, 2014.

[2] Y. Zhang, G. Zhou, K. Lin, Q. Zhang, and H. Di, “Application of latent heat thermal energy storage in buildings: State-of-the-art and outlook", Building and Environment, vol. 42, no. 2, 197-209, 2007.

[3] M. Esen, "Thermal performance of a solar-aided latent heat store used for space heating by heat pump", Solar Energy, vol. 69, pp. $15-25,2000$.

[4] B. Gin, and M. Farid, "The use of PCM panels to improve storage condition of frozen food", Journal of Food Engineering, vol. 100, pp. 372-376, 2010.

[5] Y. Weng, H. Cho, C. Chang, S. Chen, "Heat pipe with PCM for electronic cooling", Applied Energy, vol. 88, no. 5, pp.1825-1833, 2011.

[6] M. Pomianowski, P. Heiselberg, and Y. Zhang, "Review of thermal energy storage technologies based on PCM application in buildings", Building and Environment, vol. 67, pp. 56-69, 2013.

[7] F. Kuznik, D. David, K. Johannes, and J.J. Roux, "A review on phase change materials integrated in building walls", Renewable \& Sustainable Energy Reviews, vol. 15, no. 3, pp.79-91, 2011.

[8] Q. Yan, R. Huo, and L. Li, "Experimental study on the thermal properties of the phase change material wall formed by different methods". Solar Energy, vol. 86, pp. 3099-3102, 2012.

[9] I. Mandilaras, M. Stamatiadou, M. Katsourinis, D. Zannis, G. and M. Founti, "Experimental thermal characterization of a Mediterranean residential building with PCM gypsum board walls", Building and Enviornment, vol. 61, pp. 93-103, 2013.

[10] A. Sa, M. Azenha, H. Sousa, and A. Samagaio, "Thermal enhancement of plastering mortars with phase change materials: Ex- 
perimental and numerical approach. Building and Environment, vol. 49 pp. 16-27, 2012.

[11] X. Jin, M. Medina, and X. Zhang, "On the placement of a phase change material thermal shield within the cavity of buildings walls for heat transfer rate reduction. Energy", vol. 73, pp. 780-786, 2014.

[12] J. Wang, E. Long, W. Qin, and L. Xu, "Ultrathin envelope thermal performance improvement of prefab house by integrating with phase change material" Energy and Buildings, vol. 67, pp. 210-216, 2013.
[13] F. Kuznik, J. Virgone, "Experimental investigation of wallboard containing phase change material: Data for validation of numerical modeling", Energy and Buildings, vol. 5, no. 41, pp. 561-570, 2009.

[14] C. Zhang, Y. Chen, Y. L. Wu, and M. Shi, "Thermal response of brick wall filled with phase change materials (PCM) under fluctuating outdoor temperatures". Energy and Buildings, vol. 43, pp. 3514-3520, 2011.

Received: September 16, 2014

Revised: December 23, 2014

Accepted: December 31, 2014

(C) Tao et al.; Licensee Bentham Open.

This is an open access article licensed under the terms of the Creative Commons Attribution Non-Commercial License (http://creativecommons.org/licenses/by-nc/4.0/) which permits unrestricted, non-commercial use, distribution and reproduction in any medium, provided the work is properly cited. 